\title{
NAPS in 2016: why not everywhere?
}

\section{(ㅇ) $\circledast$}

Autor

Andrea Riphaus

Institutions

Department of Medicine and Gastroenterology, KRH Klinikum Agnes Karll, Laatzen, Germany

submitted 18.12 .2016

accepted after revision 30.12.2016

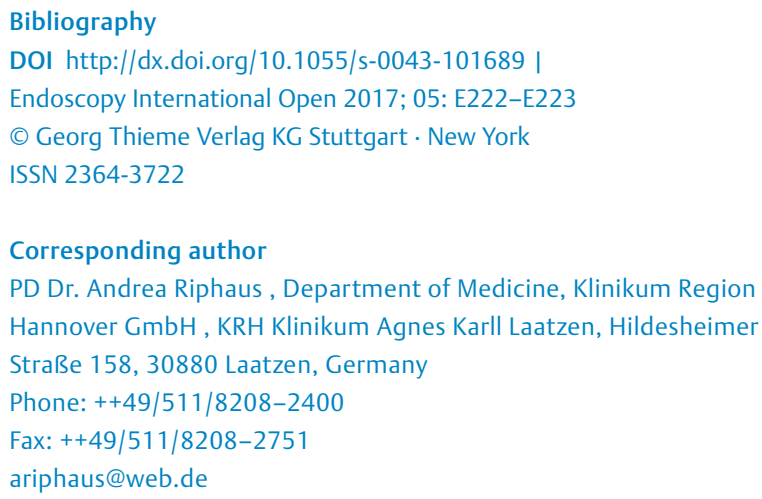

Many recently published data have shown that sedation with short-acting propofol seems to be the ideal drug for endoscopic procedures, whether for diagnostic [1-7] or therapeutic [3] purposes, even in elderly high-risk patients [8] or patients with liver cirrhosis [9]. Propofol is therefore recommended as the first choice over midazolam in currently published international guidelines [10-12]. Also many editorials for sedation in gastrointestinal endoscopy have been published over the last decade, showing that non-anesthesiologist propofol sedation (NAPS) and in particular nurse-administered propofol sedation (NAAP) is safe when performed by trained staff $[13,14]$ also when compared to anesthesiologist-administered sedation in a low-risk population $[15,16]$. Results of the trial by Sathanantha et al. [17], published in the current issue of Endoscopy International Open, also confirm the safety of physician-directed nurse-administered propofol sedation (here combined with midazolam) in low-risk patients undergoing endoscopy and colonoscopy.

Although, performance of so-called NAPS or NAAP was already endorsed by different international societal guidelines including the 4 major American societies (American Gastroenterological Association, American College of Gastroenterology, American Society for Gastroenterological Endoscopy and American Association for the Study of Liver Diseases), the European Society of Gastrointestinal Endoscopy (ESGE) and however briefly, the European Society of Anaesthesiology (ESA) this topic is still a matter of debate $[10,11]$. This committee had worked together in an attempt to improve the quality and safety of care for the patient undergoing gastrointestinal interventions. Despite the existing evidence and endorsement of different scientific societies, propofol is still underused in many countries [18] even given current evidence from several metaanalyses $[19,20]$ showing that NAPS is as safe as endoscopistdirected so-called "traditional" sedation. One reason might be the theoretical possibility of clinically significant side effects including respiratory and circulatory depression, which in fact occur at a very low rate [14]. Another reason is the position of some anesthesiology societies mainly in countries where sedation by anesthesiologist is high-priced reimbursed. However, those arguments are almost entirely devoid of any evidence base but resulted in retraction by the ESA of the initially coworked European sedation guideline [21]. However, since 2010 the guideline board of the ESA has still failed to underline their statement of guideline retraction, with evidence-based arguments as the authors of the letter to the editor did. The latest example of this comes from Portugal. After an article was published on use of propofol in colorectal cancer screening [22], anesthesiologists called on the Editorial Board to retract the text [23] without mentioning proper evidence for that action.

However, all currently available national and international guidelines, including the European guideline with anaesthesiologist in the committee, were focusing on patient safety as a precondition without any exception when sedation for gastrointestinal endoscopy is performed by non-anesthesiologists [10 - 12, 24,25]. This underscores the total agreement between gastroenterologists and anesthesiologists focusing on patient safety as the main goal. The best example in this context is the German guideline [12], showing that cooperation instead of defense might be an ideal option regarding guideline development and coordinating nationwide training courses under welldefined conditions [26, 27]. One reason that this concept is successful might be the fact that in Germany there is no reimbursement when an anesthesiologist performs propofol sedation in the ambulatory or hospital setting, whereas in other countries, an attractive reimbursement is given. Up to now more than 8000 nurses have been trained in courses performed jointly with anesthesiologists and gastroenterologists as a prerequisite for recognition and certification of the course to maximize patients' safety as well as structural and personal preconditions [28]. Especially in the hospital setting, there are too few anesthesiologists is to cover every patient undergoing gastrointestinal endoscopy with propofol as the evidence-based ideal drug in that setting. Therefore, alternative options (NAAP, NAPS) are increasingly recommended and performed in different 
countries, as propofol shows more advantages than disadvantages, when the focus is strictly on evidence instead of politics.

Interdisciplinary cooperation according to the recommendations and contents of the European curriculum for sedation training in gastrointestinal endoscopy created by ESGE under anesthesiologist expertise and European Society of Gastroenterology and Endoscopy Nurses and Associates (ESGENA) might be the goal for further discussion. After all, it is time to prove that monetary aspects may not be influencing anesthesiology societies' avoidance of NAAP, as discussed in the article by Dumonceau JM: "NAAP: It's all about money" [29].

\section{Competing interests}

None

\section{References}

[1] McQuaid KR, Laine L. A systematic review and meta-analysis of randomized, controlled trials of moderate sedation for routine endoscopic procedures. Gastrointest Endosc 2008; 67: 910 - 923

[2] Dewitt J, McGreevy K, Sherman S et al. Nurse-administered propofol sedation compared with midazolam and meperidine for EUS: a prospective, randomized trial. Gastrointest Endosc 2008; 68: 499-509

[3] Jung M, Hofmann C, Kiesslich R et al. Improvedsedationindiag- nostic and therapeutic ERCP: propofol is an alternative to midazolam. Endoscopy 2000; 32: 233-238

[4] Meining A, Semmler V, Kassem AM et al. The effect of sedation on the quality of upper gastrointestinal endoscopy: an investigator-blinded, randomized study comparing propofol with midazolam. Endoscopy 2007; 39: $345-349$

[5] Singh H, Poluha W, Cheung M et al. Propofol for sedation during coIonoscopy. Cochrane Database Syst Rev 2008; 04: DOI: 10.1002/ 14651858.CD006268.pub2

[6] Riphaus A, Gstettenbauer T, Frenz MB et al. Quality of psycho- motor recovery after propofol sedation for routine endoscopy: a ran- domized and controlled study. Endoscopy 2006; 38: 677-683

[7] Horiuchi A, Nakayama Y, Katsuyama Y et al. Safety and driving ability following low-dose propofol sedation. Digestion 2008; 78: 190-194

[8] Riphaus A, Stergiou N, Wehrmann T. Sedation with propofol for routine. ERCP in high-risk octogenarians: a randomized, controlled study. Am J Gastroenterol 2005; 100: 1957-1963

[9] Riphaus A, Lechowicz I, Frenz MB et al. Propofol sedation for upper gastrointestinal endoscopy in patients with liver cirrhosis as an alternative to midazolam to avoid acute deterioration of minimal encephalopathy: a randomized, controlled study. Scand J Gastroenterol 2009; 44: 1244 - 1251

[10] Vargo J], Cohen LB, Rex DK et al. Position statement: Nonanesthesiolo- gist administration of propofol for $\mathrm{Gl}$ endoscopy. Am J Gastroenterol 2009; 104: $2886-2892$

[11] Dumonceau JM, Riphaus A, Schreiber F et al. Non-anesthesiologist administration of propofol for gastrointestinal endoscopy: European Society of Gastrointestinal Endoscopy, European Society of Gastroenterology and Endoscopy Nurses and Associates Guideline-Updated June 2015. Endoscopy 2015; 47: 1175-89

[12] Riphaus A, Wehrmann T, Hausmann J et al. Update S3-guideline: "sedation for gastrointestinal endoscopy" 2014 (AWMF-registerno. 021/014). Z Gastroenterol 2016; 54: 58-95
[13] Singh H, Poluha W, Cheung M et al. Propofol for sedation during colonoscopy. Cochrane Database Syst Rev; 2008: CD006268

[14] Rex DK, Deenadayalu VP, Eid E et al. Endoscopist-directed administration of propofol: a worldwide safety experience. Gastroenterology 2009; 137: 1229-1237

[15] Ferreira AO, Torres J, Barjas E. Non-anesthesiologist administration of propofol sedation for colonoscopy is safe in low risk patients: results of a noninferiority randomized controlled trial. Endoscopy 2016; 48: $747-753$

[16] Lagasse RS. Anesthesia safety: model or myth? A review of the published literature and analysis of current original data Anesthesiology 2002; 97: $1609-1617$

[17] Sathananthan D, Young E, Nind G et al. Assessing the safety of physiciandirected nurse administered propofol sedation in low risk patients undergoing endoscopy and colonoscopy. Endoscopy International Open 2017; 05: E110-E115

[18] Riphaus A, Macias-Gomez C, Devière J et al. Propofol, the preferred sedation for screening colonoscopy, is underused. Results of an international survey. Dig Liver Dis 2012; 44: 389-392

[19] Singh H, Poluha W, Cheung M et al. Propofol for sedation during colonoscopy. Cochrane Database Syst Rev; 2008: CD006268

[20] Wang D, Chen C, Chen J et al. The use of propofol as a sedative agent in gastrointestinal endoscopy: a meta- analysis. PloS one 2013; 8: e53311

[21] Perel A. Non-anaesthesiologists should not be allowed to administer propofol for procedural sedation: a Consensus Statement of 21 European National Societies of Anaesthesia. Eur J Anaesthesiol 2011; 28: $580-584$

[22] Ferreira AO, Riphaus A. Propofol to increase colorectal cancer screening in Portugal. Acta Med Port 2014; 27: 541 - 542

[23] Almeida Lobo F1, Rodrigues Melo A. Letters to the editor concerning the article: Alexandre Oliveira Ferreira, Andrea Riphaus. Propofol to increase colorectal cancer screening in Portugal. Acta Med Port 2014; 27: $541-542$

[24] Dumonceau JM, Riphaus A, Aparicio JR et al. NAAP Task Force Members. European Society of Gastrointestinal Endoscopy, European Society of Gastroenterology and Endoscopy Nurses and Associates, and the European Society of Anaesthesiology Guideline: Non-anesthesiologist administration of propofol for Gl endoscopy. Eur J Anaesthesiol 2010; 27: 1016-1030

[25] Byrne MF, Chiba N, Singh $\mathrm{H}$ et al. Clinical Affairs Committee of the Canadian Association of Gastroenterology.Propofol use for sedation during endoscopy in adults: a Canadian Association of Gastroenterology position statement. Can J Gastroenterol 2008; 22: 457-459

[26] Beilenhoff U, Engelke M, Kern-Waechter E et al. DEGEA-Curriculum (Curriculum of the German Society of Endoscopy Nurses and Associates): Sedation and emergency management in endoscopy for endoscopy nurses and associates. http://www.degea.de/cms/fileadmin/Fachinformationen/Sedierung/DEGEA-Curriculum_english_version.pdf (Accessed: July 10 2012)

[27] Dumonceau JM, Riphaus A, Beilenhoff U et al. European curriculum for sedation training in gastrointestinal endoscopy: position statement of the European Society of Gastrointestinal Endoscopy (ESGE) and European Society of Gastroenterology and Endoscopy Nurses and Associates (ESGENA). Endoscopy 2013; 45: 496-504

[28] Schilling D, Leicht $K$, Beilenhoff $U$ et al. Impact of S3 training courses "Sedation and Emergency Management in Endoscopy for Endoscopy Nurses and Assisting Personnel" on the process and structure quality in gastroenterological endoscopy in practices and clinics - results of a nationwide survey. Z Gastroenterol 2013; 51: 619-627

[29] Dumonceau JM. Nonanesthesiologist administration of propofol: it's all about money. Endoscopy 2012; 44: 453-455 